\title{
Experimental Study on Flow and Sediment Distribution at Off-Take Channel
}

\author{
Lamisa Malik and M. Abdul Matin
}

\begin{abstract}
River off-take is one of the complex features in fluvial systems and the distribution of flow, and sediments along the branches are still a matter of research. This paper deals with a physical simulation on an off-take channel for understanding the flow and sediment distribution in the vicinity Laboratory-based test runs have been carried out by changing the discharges and the angles off-take. A total of eighteen test runs have been conducted for three discharge conditions with three off-take angles. Two equations for predicting water and sediment discharge ratios have been proposed as a function of Froude number, channel geometry and off-take angel. Flow visualizations have also been carried out in the vicinity of the off-take for understanding erosion and sedimentation pattern. Flow and sediment movement patterns were carefully observed during the simulation and four distinguished zone formations have been noted in the vicinity. Finally, validations of the developed equations have been done with the field data from selected river off-take systems of Bangladesh. Validation results of field data show mean discrepancy ratios of 0.83 for the discharge equation and 0.89 for sediment equation during low flow.
\end{abstract}

Index Terms-Flow distribution, offtake angles, physical modeling, rivers of Bangladesh, sediment distribution.

\section{INTRODUCTION}

When the main river channel bifurcates into two channels, the point of bifurcation is called off-take of the bifurcated channel. Bifurcations occur, for example in river deltas, where a river flows into the sea or lake or in braided rivers where individual channels combine and then separate repeatedly. Over the last 25 years much concentration was given on studying flows at river confluences but there was a lack of research on understanding the flow behaviour when channel bifurcates. Although ongoing research is beginning to fill in some of these gaps in our understanding through the laboratory experiments and mathematical models, this has not been matched by sufficient progress in measuring and quantifying the bifurcation process in natural river channels.

Previous studies on the flow and sediment distributions at symmetrical channel bifurcation in laboratory experiments showed that no general relation can be expected in case of sediment distribution over two downstream branches of bifurcation [1]-[4], due to its dependency on both branch channels and nose geometries [5]. Flow and sedimentation

Manuscript received May 2, 2020; revised November 24, 2020. This work was funded by Bangladesh University of Engineering and Technology (BUET).

Lamisa Malik is with University of Waterloo, ON, CA. she is also with Bangladesh University of Engineering and Technology (BUET), Bangladesh (e-mail: lamisa.m.aurchi005@gmail.com).

M. Abdul Matin is with the Department of Water Resources Engineering at BUET, Bangladesh (e-mail: matinma81@gmail.com). patterns have also been observed with the help of physical and mathematical simulation for non- symmetric bifurcation channels [6]-[15]. Obasi investigated the effect of off-take angles on the flow distribution at a concave channel bifurcation in a metal flume and derived an equation showing that the off-take discharge increased positively with increases in off-take angles as well as main channel discharges [6], [7] Although, other study showed that the discharge distribution is governed by the conveyance capacity and hydraulic gradient of bifurcation with the condition that water levels at the bifurcation point must be the same [8], [16]. However, sediment transport is strongly influenced by the secondary flow patterns [17] and local conditions at the bifurcation point [18].

Several works have been conducted in light of the 1-D nodal point relationship, which was pointed out by Wang [4], [19]. Based on that general equation, the necessity of incorporating width ratio of two channels was observed because the widths of channels have a strong influence on the equilibrium position [20]. Simulation and statistical analyses were also carried out on river bifurcations in gravel braided networks [11], [21] within the context of the nodal point equation which proposed an alternative formulation of nodal point conditions. Another study on sediment distribution at bifurcation points of natural rivers and artificial channel revealed that the curvature effect at the bifurcation and immediately upstream of the bifurcation is very important for the sediment distribution and the nodal point equation is highly variable on the configuration and the geometry of bifurcation [22].

Recommendations were also made on maintaining small off-take angle in canals. Whereas, too small off-take angles will erode the bank between the branch canal and the main canal, which could gradually lead to flooding and eventual destruction of the canal [23]. Employment of spur dyke was suggested for off-take restoration because it would prevent flushing sediment from the vicinity [24].

Most of the studies conducted on channel bifurcation were mainly for symmetrical or non-symmetrical nose without any special reference of Rivers of Bangladesh. As a result, hydraulics of flow and sediment transport in the vicinity of river off-take is yet to be understood properly for river analyses and management. It is difficult to study the hydraulics and morphological behaviour of the bifurcation in rivers both in the laboratory and in the field. However, no notable experimental works have been carried out on bifurcation at the off-take channel with reference to Bangladesh. Although two studies were conducted on the morphology of symmetrical river bifurcation on an experimental setup built in the Hydraulics and River Engineering Laboratory of Bangladesh University of Engineering and Technology [5] [2]. But their study 
concentrates only on the distribution of the discharge and sediment with nose angle and shape of the nose junction as a major variable for symmetrical case.

In this study, the hydraulics of flow and sediment transport in the main channel and in the vicinity of river off-take was conducted for a proper understanding of the flow and sediment transport behaviours. Laboratory experimentation for different off-take angles with the varying discharge was carried out for this purpose. Dimensionless groups have been formed to develop a theoretical relationship among various hydraulic parameters. Simulated data have been used to obtain exponents and coefficients of the developed equations for predicting flow and sediment distribution in off-take. The developed equation has been verified by possible similar field conditions with considerable modification. To achieve the objectives of the study, stepwise methodologies have been used. These steps are theoretical study, experimental channel design, data collection, observation and analysis.

\section{DeVElopment OF Dimensionless EQUATION}

Flow determination through a channel is dependent on various fluid properties such as channel geometry and properties of bed and bank material. Following Governing parameters have been decided for each channel to determine the equation for discharge on the main and off-take channel.

$$
Q_{1}, Q_{2}, B_{1}, B_{2}, Y_{1}, Y_{2}, \rho, \mu, \Theta, S
$$

where $Q$ is the discharge, $B$ is the width, $Y$ is the flow depth and subscript 1 and 2 indicate upstream of the main channel and off-take channel respectively. $\rho$ is the density of fluid, $\mu$ is the viscosity of fluid, $\Theta$ is the angle of off-take and $\mathrm{S}$ is the slope of the channel. Rayleigh's method of dimensional analysis has been used for the formation of dimensionless equations. This form of dimensional analysis expresses a functional relationship of some variables in the form of an exponential equation.

Thus for the moderate slope with variable off-take angle equation can be proposed to predict discharge of off-take channel.

$$
\frac{Q_{2}}{Q_{1}}=\mathrm{a}_{\boldsymbol{\theta}} \cdot\left(\frac{\nu}{q_{1}}\right)^{\mathrm{b}_{\boldsymbol{\theta}}}\left(\frac{B_{2}}{B_{1}}\right)^{C_{\boldsymbol{\theta}}}\left(\frac{F r_{2}}{F r_{1}}\right)^{d_{\boldsymbol{\theta}}} \cdot \theta \cdot S
$$

where, values of $a_{\theta}, b_{\theta}, c_{\theta}$ and $d_{\theta}$ have been evaluated from simulation.

\section{Simulation}

Simulation data were collected from a sand bed facility located in the Hydraulics and River Engineering Laboratory of Water Resources Engineering Department (DWRE) of Bangladesh University of Engineering and Technology. The experimental setup consisted of two separate parts; the experimental reach and experimental facilities. Experimental reach was a $11 \mathrm{~m}$ long and $1 \mathrm{~m}$ wide main channel and a 40 $\mathrm{cm}$ wide off-take channel similar to the model of a small scale river off-take. Sand samples were washed and sieve analysis was performed. Sand grain size of $\mathrm{D}_{50}=0.23 \mathrm{~mm}$ was used
[25]. The schematic diagram of the flow circulation system in the experimental setup is shown in Fig. 1.

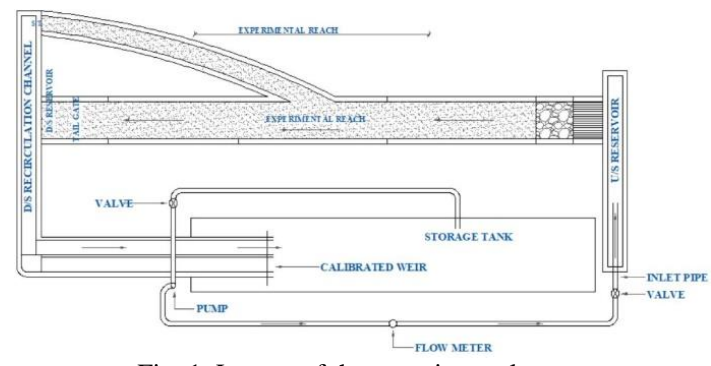

Fig. 1. Layout of the experimental setup.

\section{A. Design Criteria and Data Collection}

First, the model was constructed according to available laboratory flume facilities and Froude law criteria. Reconnaissance test runs were made on the main channel to identify necessary changes to reconstruct the channel. Effective flow area of the channel was increased by reconstructing it into a rectangular channel. Preliminary test runs were conducted in order to find the applicability of sediment transport equations for this model.

The first step of the simulation was to select discharge ranges and fixation of the discharge values. Tailgates were lifted to a position so that the maximum depth of water flows into the channel without three vertical points on each segment. Velocity profile was plotted and velocity of $0.6 \mathrm{Y}$ depth from the surface of the water was considered as depth average velocity of that segment. Average of depth average velocities of three segments were considered as the average velocity of that cross-section. Samples for suspended sediment load calculations were collected and oven-dried. The same procedure was repeated during the simulation of the entire set of test run.

\section{SimUlation SCENARIOS}

For the purpose of data collection, four sets of observation were carried out with a varying off-take angle (20, 40 and 60 degrees) and each set with varying input discharge $(0.09$, 0.06 and $0.03 \mathrm{~m}^{3} / \mathrm{s}$ ). Sixteen test runs were conducted for the development of the two equations and two additional runs for observation of flow and sediment behaviour. However, sediment flow measurements were made only for the maximum discharge of $0.09 \mathrm{~m}^{3} / \mathrm{s}$. Simulation Scenarios' with flow and sediment discharges are shown in Table 1 . Where, $\mathrm{Q}_{1}$ and $\mathrm{Q}_{2}$ are the discharges for the main channel and off-take channel respectively; $\mathrm{Q}_{\mathrm{s} 1}$ and $\mathrm{Q}_{\mathrm{s} 2}$ are the sediment discharges for main channel and off-take channel respectively and $\sigma$ is the change in relative sediment distribution over relative flow distribution, expressed in terms of $\left(\mathrm{Q}_{\mathrm{s} 2} / \mathrm{Q}_{\mathrm{s} 1}\right) /\left(\mathrm{Q}_{2} / \mathrm{Q}_{1}\right)$. It is observed from Table I that water and sediment discharge ratios of off-take to the main channel, both increases with the increase of off-take angles. This means for greater off-take angles more water would flow and more suspended sediment will flush through the system. Value of $\sigma$ indicates relative sediment input to a channel compared to discharge input and it increases from 0.49 to 0.71 with the increase of off-take angles. It indicates that, the higher the value of $\sigma$, the larger the amount of sediment enters into the off-take channel. 
TABLE I: SIMULATION SCENARIOS AND THEIR RESULTS WITH VARIOUS FLOW AND SEDIMENT DISCHARGE CONDITIONS

\begin{tabular}{|c|c|c|c|c|c|c|c|c|}
\hline Test Runs & $\begin{array}{c}\text { Offtake Angle } \\
\text { (Degree) }\end{array}$ & $Q_{1}\left(\mathrm{~m}^{3} / \mathrm{s}\right)$ & $Q_{2}\left(m^{3} / s\right)$ & $Q_{s 1}($ ton $/ d)$ & $Q_{s 1}($ ton $/ d)$ & $Q_{2} / Q_{1}$ & $Q_{s 2} / Q_{s} 1$ & $\overline{c \sigma}$ \\
\hline Run 1 & NO off-take & 0.0879 & .. &.. & . & .. & .. &.. \\
\hline Run 2 & & 0.0554 & .. & .. & .. & .. & .. & .. \\
\hline Run 3 & & 0.0293 & .. & .. & .. & .. & .. & .. \\
\hline Run 4 & & 0.0990 & .. & 7.3181 & .. & .. & .. & .. \\
\hline Run 5 & 20 & 0.0697 & 0.0304 & .. & .. & 0.4366 & .. & .. \\
\hline Run 6 & & 0.0549 & 0.0188 & .. & .. & 0.3420 & .. & .. \\
\hline Run 7 & & 0.0314 & 0.0123 & .. & .. & 0.3918 & .. & .. \\
\hline Run 8 & & 0.0850 & 0.0432 & 7.1340 & 1.5523 & 0.5082 & 0.2176 & 0.4281 \\
\hline Run 9 & 40 & 0.0887 & 0.0360 & .. & .. & 0.4061 & .. & .. \\
\hline Run 10 & & 0.0505 & 0.0194 & .. & .. & 0.3835 & .. & .. \\
\hline Run 11 & & 0.0336 & 0.0107 & .. & .. & 0.3198 & .. & .. \\
\hline Run 12 & & 0.0900 & 0.0370 & 6.3262 & 1.5150 & 0.4108 & 0.2395 & 0.5830 \\
\hline Run 13 & 60 & 0.0888 & 0.0363 & .. & .. & 0.4093 & .. & .. \\
\hline Run 14 & & 0.0600 & 0.0347 &.. & .. & 0.5791 & .. & .. \\
\hline Run 15 & & 0.0332 & 0.0218 & .. & . & 0.6563 & .. & .. \\
\hline Run 16 & & 0.0906 & 0.0486 & 5.3894 & 2.0505 & 0.5364 & 0.3805 & 0.7093 \\
\hline
\end{tabular}

\section{Simulated Findings}

The simulation observation was made to understand the direction of flow velocity, siltation and erosion pattern at the test section. During the simulation, the following observations were made near the off-take region. Turbulent eddies were formed due to the flow separation of streamlines at the nose and it was observed at the junction for both downstream channels. Flow separation was causing streamlines to form eddy, which decreases the linear flow velocity of the region. However, they were also observed to penetrate the laminar sub-layer along the bed and, consequently, erosion in that region.

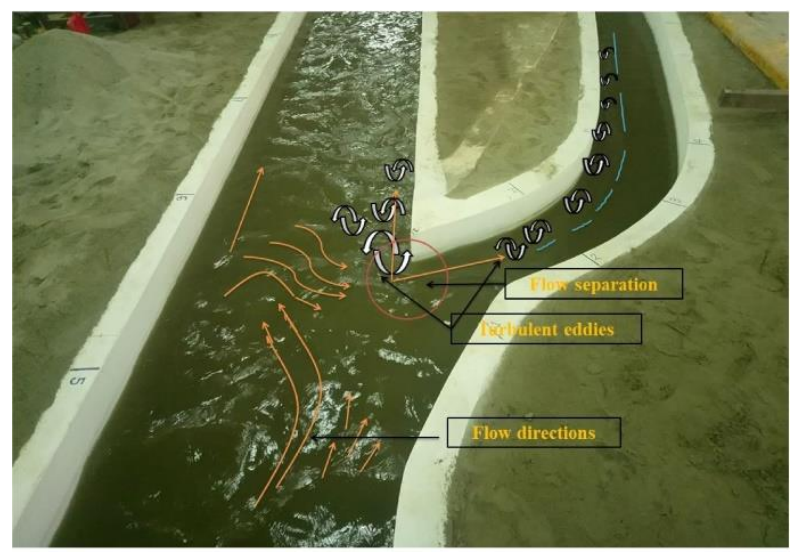

Fig. 2. Observation of the flow behaviour in the vicinity of the off-take section.

Streamlines were observed to deviate from the straight uniform configuration as it approaches near the off-take. As shown in Fig. 2, streamlines of middle to left segment at upstream parent channel bend toward left. Whereas near $\mathrm{t} h \mathrm{e}$ junction zone, streamlines bend toward the off-take and obliquely enter into it.

Silting and erosion phenomena at the surrounding off-take region was observed by measuring bed elevations. Due to the configuration of the experimental channel, sedimentation occurred at the outer side and erosion at the mouth of offtake. This allows us to rethink the configuration of off-take to prevent siltation at the mouth. According to Bulle effect [26] more sediment was diverted into the lateral channel than in the straight channel due to the helical flow. The concentration of suspended sediment became higher near the bed and, therefore, the helical flow would also change the direction of suspended sediment transport with respect to the depth-averaged velocity and its direction. The junction zone of the main channel and off-take can be said to have four zones as per observations which is shown in Fig. 3.

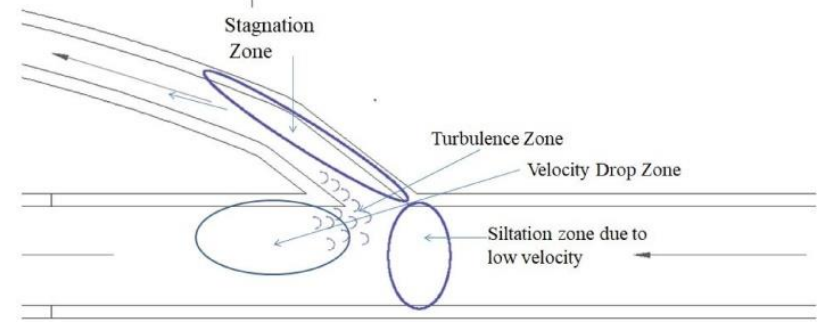

Fig. 3. Observed flow zones near the main channel and offtake channel junction.

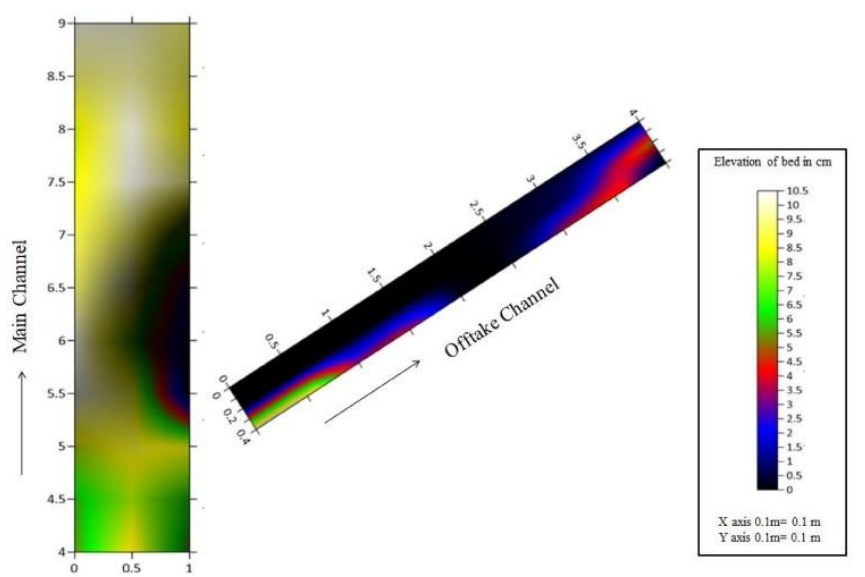

Fig. 4. Bed elevation change within the simulated reach for $\theta=60$ degrees.

The stagnation zone occurred near the upstream of the offtake, where the reduction in velocity caused the particles to stay in bed. Conversely, the turbulence zone at the nose of the off-take caused erosion in that region. The velocity drop zone was developed due to rapid velocity reduction near the downstream junction wall which was induced by the sudden transition in a channel. Due to this high turbulence near the wall of the channel, all particles present in the sand bed before the simulation were washed away, creating erosion zone just after the siltation zone. However, the creation of a turbulent and stagnation zone caused the flow line to deviate 
from the parallel path. Thus the irregular movement induced sedimentation just at the outer edge of the mouth of the offtake channel as in Fig. 4.

\section{ANAlysis OF HydRAUlic PARAMETERS OF TEST RUNS}

Test sections were selected in such a way that the velocity variation was minimized and uniform flow was maintained throughout the channel. Flow, conveyance capacities, hydraulic parameters (water depths, velocities and water surface slopes) were measured to obtain flow and sediment discharges. It has been observed that water depths and velocities vary for in same discharge with different off-take angles.

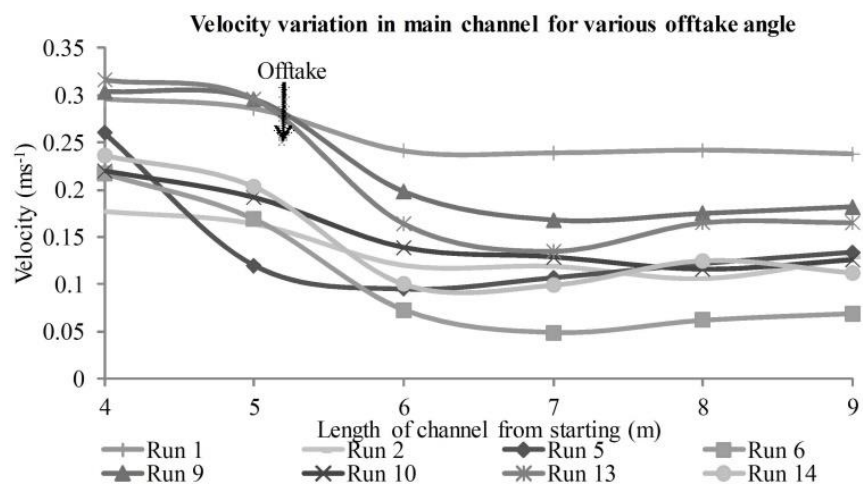

Fig. 5. Velocity variation on main channel for various off-take angle.

Fig. 5 and Fig. 6 show velocities variation in the main channel for different off-take angles. As the off-take angle increases, the velocity in the off-take channel increases, while the velocity of flow in the downstream end of the main channel decreases. It was also observed from the figures that the relative downstream velocity of main to off-take channel increases with the increase of off-take angle.

The junction of the channel is the most critical point for a canal system because of its vulnerability to silt due to the stagnation of flow and formation of turbulence at the nose. Velocity variation at the junction for different angles in the experimental setup has been plotted and the velocities at the edges of the channel are higher than the middle section due to turbulence in Fig. 7 to Fig. 9.

Velocity variation at offtake for various offtake angle

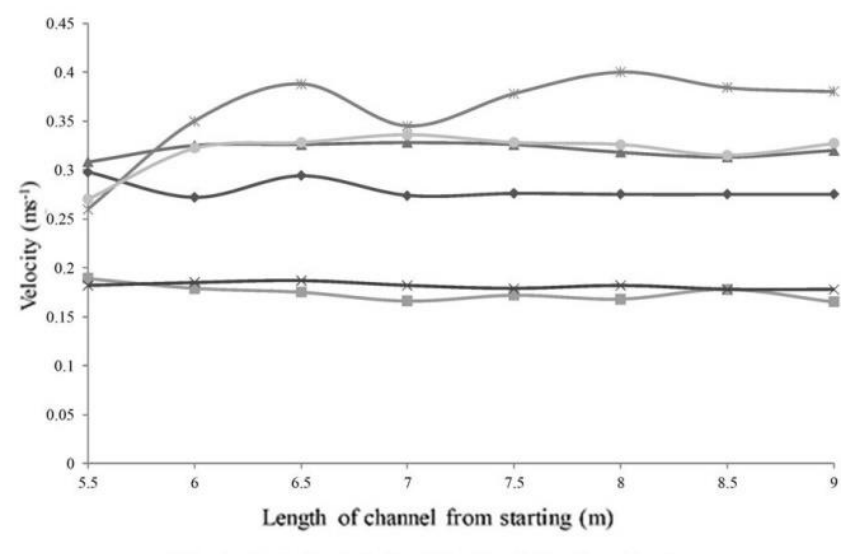

$\rightarrow$ Run $5 \rightarrow$ Run $6 \rightarrow$ Run $9 \rightarrow$ Run $10 \nrightarrow$ Run $13 \rightarrow$ Run 14

Fig. 6. Velocity variation at off-take channel for various off-take angle.

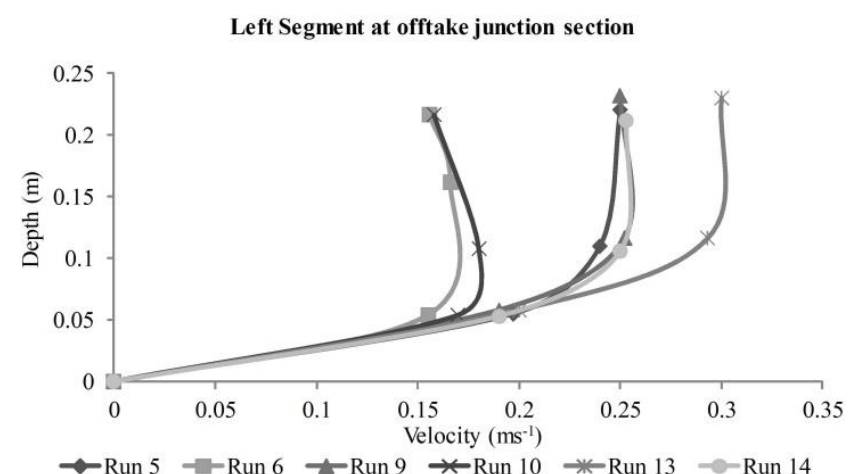

Fig. 7. Velocity variation at off-take junction (left segment).

Middle segment at offtake junction section

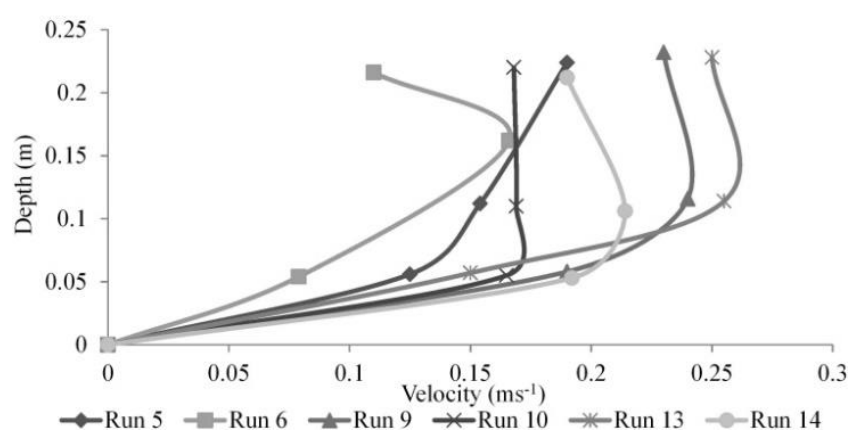

Fig. 8. Velocity variation at off-take junction (middle segment).

Off-take did not have a significant effect on the left segment of the junction section velocity. But for the middle and right segments, an increase in off-take angle resulted in an increase in velocity at the mouth of the off-take. The velocity profiles in the junction were found to be slightly irregular when compared to the typical velocity distribution profile. This irregularity may be due to the development of secondary current and stagnation zone at the junction of the off-take and main channel.

Right segment at offtake junction section

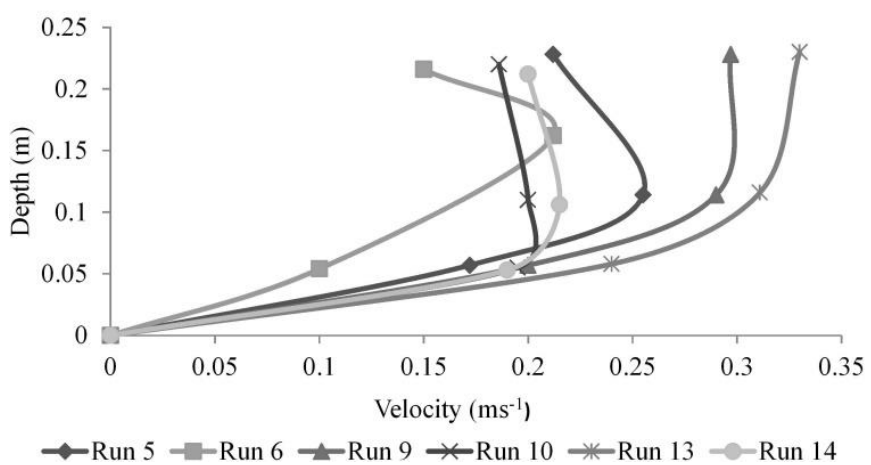

Fig. 9. Velocity variation at off-take junction (right segment).

\section{Development of Equation for Water Discharge Distribution}

The dimensional analysis provided a functional relationship of dependent variables in the form of an exponential equation as shown in (2). Dimensionless terms and their relations with the off-take angle have been shown in Table II. Thus for the moderate slope with variable off-take angle (2) can be proposed to predict discharge of off-take channel with parameters of Table II.

Fig. 10 to Fig. 12 show more than 90 percent co-relation for all the three cases [25] and the discrepancy ratios vary between 0.87 - 1.2. The discrepancy ratio (DR) between 0.5 to 1.5 is considered as a good prediction in river engineering 
and thus predictability of the proposed equation is considered satisfactory.

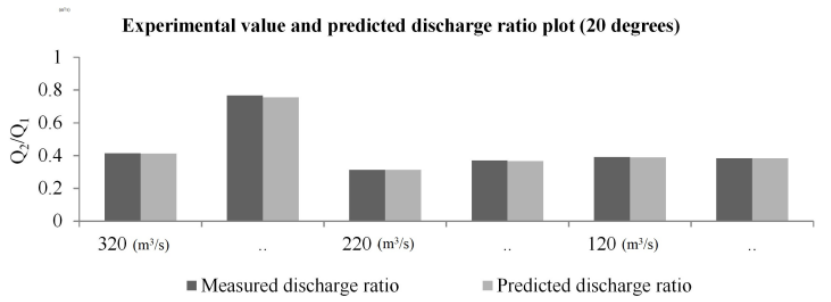

Fig. 10. Simulated vs. predicted $Q_{2} / Q_{1}$ values from equations for 20 degrees off-take angle.

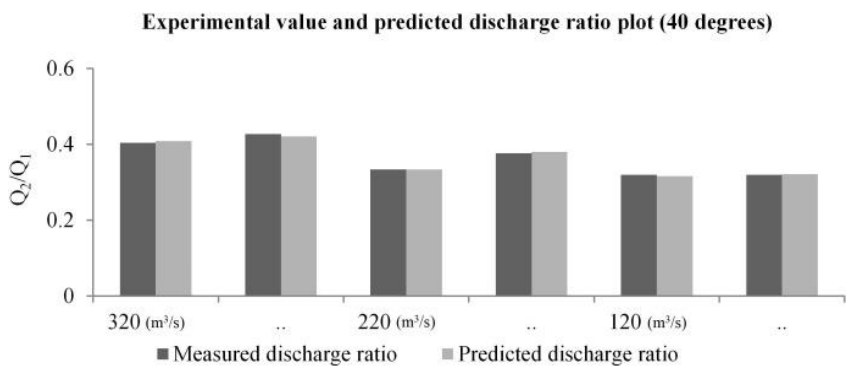

Fig. 11. Simulated vs. predicted $Q_{2} / Q_{1}$ values from equations for 40 degrees off-take angle.

Experimental value and predicted discharge ratio plot (60 degrees)

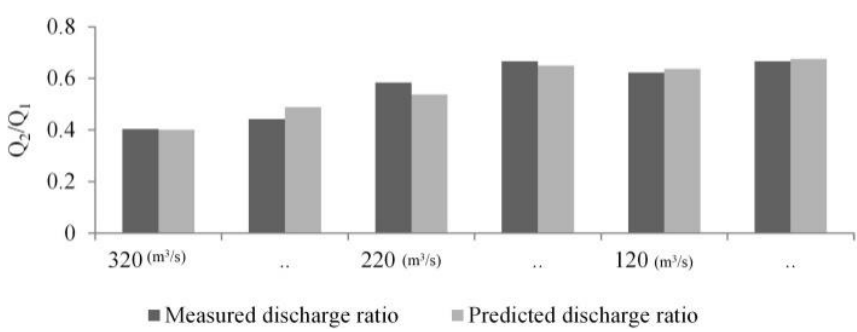

Fig. 12. Simulated vs. predicted $Q_{2} / Q_{1}$ values from equations for 60 degrees off-take angle.

\section{SEDIMENT TRANSPORT}

Sediment data were compared with three sediment transport formulas Ackers-White [27], Engelund-Hansen [28] and Van Rijn [29]. Table III shows a higher diverting angle attracts more suspended sediment load, and sediment discharge was proportional to the water discharge. It was also observed that Ackers-White formula predicts sediment discharge reasonably where Engelund-Hansen formula overestimated and Van Rijn formula underestimated the results.

Combining general equation of 1D nodal point proposed by Islam [2] and modified equation for concave off-take proposed by Obasi [7] following relationship has been given for sediment distribution in off-take channel where, $q_{1}$ is the specific discharge for upstream of main channel, $q_{2}$ is the specific discharge for off-take channel and $\mathrm{x}, \mathrm{y}, \mathrm{z}$ are the powers of dimensionless terms respectively.

$$
\frac{Q_{S 2}}{Q_{S 1}}=x\left(\frac{q_{2}}{q_{1}}\right)^{y} \theta^{z}
$$

To determine the value of $\mathrm{x}, \mathrm{y}$ and $\mathrm{z}$ analysis were made on simulation results. Proposed equation for sediment discharge ratio of the off-take channel to the upstream main channel is as follows

$$
\frac{Q_{S 2}}{Q_{S 1}}=0.043\left(\frac{q_{2}}{q_{1}}\right)^{1.039} \theta^{0.458}
$$

Proposed formula has been compared to Obasi's proposed formula which is shown in Fig. 13.

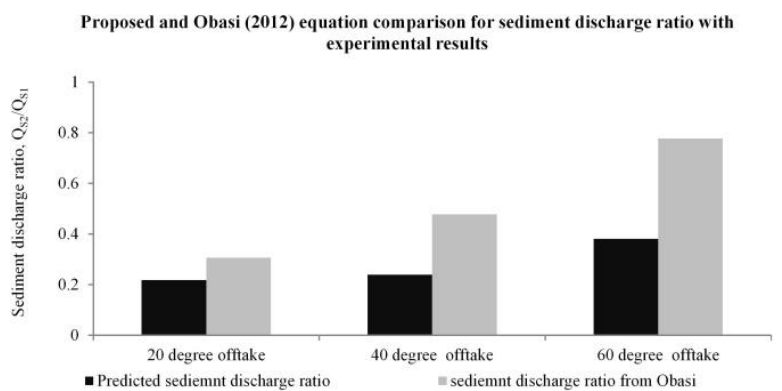

Fig. 13. Comparison between Proposed and Obasi for sediment discharge ratio.

\section{COMPARISON OF PROPOSED PREDICTION EQUATIONS WITH FIELD DATA}

In order to do that, a reconnaissance study was conducted on the river off-takes of Bangladesh to identify the nearly similar off-take bifurcation system to the simulation configuration. Considering the availability of Bangladesh Water Development Board (BWDB) data, four off-take systems of Bangladesh, Upper Korotoya-Dhepa, Surma-Botor Khal (off-take of Surma), Old Brahmaputra-Jhenai off-take and Ganges-Gorai has been taken for a relative comparison of the proposed flow discharge distribution equation. But for sediment discharge comparison, off-take of Ganges-Gorai has only been taken into consideration due to lack of available sediment data for other selected rivers.

\begin{tabular}{|c|c|}
\hline Power of dimensionless term & Equation in terms of offtake angle \\
\hline $\mathrm{a}$ & $a_{\theta}=0.008 \theta+9.624$ \\
\hline $\mathrm{b}$ & $b_{\theta}=0.012 \theta-0.517$ \\
\hline $\mathrm{c}$ & $c_{\theta}=-0.084 \theta+4.908$ \\
\hline $\mathrm{d}$ & $d_{\theta}=0.008 \theta+0.475$ \\
\hline
\end{tabular}

TABLE II: TREND OF EXPONENT OF DIMENSIONLESS TERM

\section{A. Comparison of Discharge Ratio}

Discharge ratio (2) was determined by using constant cross-sectional area, average width and regime slope. As such, a width correction factor has been introduced in (6) for accounting variation of width of the channel. An exponent of width ratio $\left(B_{2} / B_{1}\right)$ has been multiplied by a factor C'.

$$
C^{J}=0.1802-0.0041 \theta
$$

So the modified equation for field condition is as follows

$$
\frac{Q_{2}}{Q_{1}}=a_{\theta} \cdot\left(\frac{v}{q_{1}}\right)^{b_{\theta}}\left(\frac{B_{2}}{B_{1}}\right)^{c_{\theta}^{\prime}}\left(\frac{F r_{2}}{F r_{1}}\right)^{d_{\theta}} \cdot \theta \cdot S
$$

where,

$$
c^{\prime}{ }_{\theta}=C^{\prime} \cdot c_{\theta}=3.44 X 10^{-4} \boldsymbol{\theta}^{2}-0.035 \boldsymbol{\theta}+0.8844
$$


The value obtained from (6) and (7) discharge ratio values are tabulated in Table IV. The degree of compliance of the proposed equation can be seen in Fig. 14. The line shows discrepancies of predicted and observed value for both simulated and field conditions.

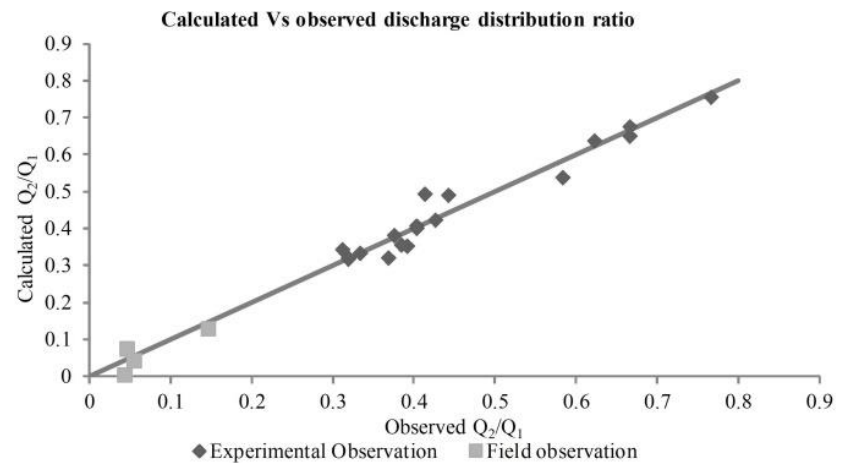

Fig. 14. Predicted Vs. observed discharge distribution ratio.

\section{B. Comparison of Sediment Discharge Distribution}

Values obtained from field sediment concentration has been considered as field observed sediment discharge and values predicted using (4) has been considered as predicted sediment discharge. Both values are plotted in Fig. 15 which shows a good match between predicted and field observed. The discrepancy ratio varies from 0.64 to 1.18 for high flow whereas for high flow during monsoon and post-monsoon season discrepancy ratio varies from 0.08 to 2.87 .

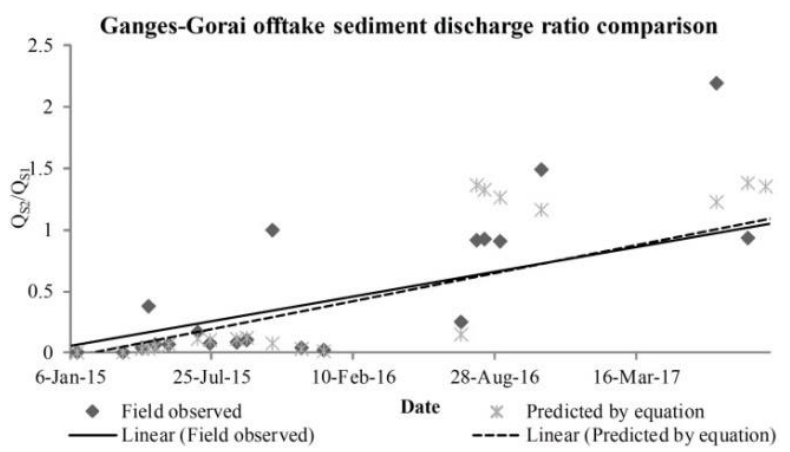

Fig. 15. Predicted and observed sediment discharge distribution ratio comparison for Ganges-Gorai offtake.

TABLE III: COMPARISON TABLE FOR SEDIMENT DISCHARGE CALCULATION

\begin{tabular}{|c|c|c|c|c|c|}
\hline \multirow[t]{2}{*}{ Angle (degrees) } & \multicolumn{5}{|c|}{ Sediment discharge (ton/day) } \\
\hline & Channel & Simulated values & Ackers-White & Engelund-Hansen & Van Rijn \\
\hline \multirow[t]{2}{*}{ No off-take } & main & 7.3181 & 3.109 & 26.3999 & 0.6477 \\
\hline & .. & .. & .. & .. & .. \\
\hline \multirow[t]{2}{*}{20} & upstream main & 7.134 & 3.1768 & 20.8349 & 0.9008 \\
\hline & offtake & 1.5523 & 3.2268 & 8.8177 & 1.1715 \\
\hline \multirow[t]{2}{*}{40} & upstream main & 6.3262 & 3.3884 & 23.286 & 0.9189 \\
\hline & offtake & 1.515 & 1.5698 & 6.253 & 0.4186 \\
\hline \multirow[t]{2}{*}{60} & upstream main & 5.3894 & 4.3077 & 24.9874 & 1.4594 \\
\hline & offtake & 2.0505 & 4.1808 & 10.7311 & 1.515 \\
\hline
\end{tabular}

TABLE IV: COMPARISON TABLE FOR SEDIMENT DISCHARGE CALCULATION

\begin{tabular}{lccc}
\hline \hline River Off-take System Name & Field Observed $Q_{2} / Q_{1}$ & Predicted $Q_{2} / Q_{1}$ & Discrepancy Ratio \\
\hline Upper Korotoya- Dhepa & 0.046 & 0.08 & 1.58 \\
Surma- Botor Khal & 0.147 & 0.135 & 0.87 \\
Old Brahmaputra- Jhenai & 0.055 & 0.042 & 0.77 \\
Ganges -Gorai & 0.05 & 0.0042 & 0.1 \\
\hline
\end{tabular}

\section{CONCLUSION}

In this study, simulation was conducted three for different discharges with three different angles for understanding and predicting the flow and sediment distribution at river off-take. It was found that water discharge, sediment discharge ratios and $\sigma$ values of off-take to the main channel increase with the increase of off-take angle. Simulated observations were also made to understand the flow and sediment transport behaviour in the vicinity of off-take channels. Two relationships was derived and proposed for the prediction of flow and sediment distribution of the main and off-take channels. To verify the predictive performance of the developed equations field data was collected from the selected river off-take system of Bangladesh. The discrepancy ratios for off-takes named Korotoya-Dhepa, Surma-Botor Khal and Old Brahmaputra- Jhenai off-take are found to be reasonably satisfactory. Similarly, the performance of the proposed equation for sediment discharge ratio calculation was only been made for the Ganges-Gorai river off-take system. A comparison with the field data shows the reasonable accuracy of both proposed equations. It can be conclude that, the results obtained and thus equations deduced from this study may be utilized in possible similar field conditions

\section{CONFLICT OF INTEREST}

The authors declare no conflict of interest.

\section{AUTHOR CONTRIBUTIONS}

The first author was responsible for conducting the experiment and writing the article. The second author was the mentor of the first author who provided guidance and important feedback with his knowledge and experience over the course of the study. Both authors approved the final version of the work.

\section{ACKNOWLEDGMENT}

The author would like to thank her supervisor for guidance and the staff of the Hydraulics and River Engineering Labora- tory of DWRE for their assistance during the experimentation. The author would also like to acknowledge 
the BUET for funding to run the experiment.

\section{REFERENCES}

[1] W. Bertoldi, "River bifurcations," Ph.D. dissertation, University of Trento, 2004.

[2] G. Islam, "Laboratory study of influence of nose angle on sediment distribution at channel bifurcation," MSc Engineering thesis, Bangladesh Univ. of Engineering and Technology, Dhaka, Bangladesh, 1996.

[3] E. Mosselman and C. Sloff, "Morphology of river bifurcations: Theory, field measurements and modelling," in Proc. Gravel-bed Rivers VI Conference, September, 2005, pp. 5-9.

[4] Z. B. Wang and T. Kaaij, "Morphodynamic development of secondary channel systems along rhine branches in the netherlands," Q1963, 1994.

[5] A. Hannan, "Laboratory study of sediment distribution at channel bifurcation," 1995.

[6] N. Obasi, J. Agunwamba, and N. Egbuniwe, "Influence of off-take angles on flow distribution pattern at concave channel bifurcation," Nigerian Journal of Technology, vol. 27, no. 2, pp. 46-57, 2008.

[7] D. A. Obasi and Agunwamba, "Effect of offtake angles on spatial distribution of silt materials at concave channel bifurcation," 2012.

[8] M. Kleinhans, B. Jagers, E. Mosselman, and K. Sloff, "Effect of upstream meanders on bifurcation stability and sediment division in 1d, 2d and 3d models," River Flow 2006, pp. 1355-1362, 2006.

[9] B. Federici and C. Paola, "Dynamics of channel bifurcations in noncohesive sediments," Water Resources Research, vol. 39, no. 6, 2003

[10] M. A. Imteaz and K. I. Hassan, "Hydraulic impacts of jamuna bridge; mitigation option," in Proc. 6th Conference on Hydraulics in Civi Engineering: The State of Hydraulics, Institution of Engineers, Australia, 2001, p. 421.

[11] M. B. Pittaluga, R. Repetto, and M. Tubino, "Channel bifurcation in braided rivers: Equilibrium configurations and stability," Water Resources Research, vol. 39, no. 3, 2003.

[12] S. K. Hore, M. H. Sarker, M. R. Ferdous, M. Ahsan, and M. I. Hasan, "Study of the off-take dynamics for restoring the gorai river," presented at 4th International Conference on Water \& Flood Management, Dhaka, 2013.

[13] A. S. Shettar and K. K. Murthy, "A numerical study of division of flow in open channels," Journal of Hydraulic Research, vol. 34, no. 5, pp. 651-675, 1996

[14] F. Noor, "Morphological study of old brahmaputra offtake using twodimensional mathematical model," 2013.

[15] M. Zaman, "Mathematical modelling study on river improvement of old brahmaputra system," 2017.

[16] P. Jansen, "Ph.(1979), 'principles of river engineering'," Pitman (London).

[17] W. R. Richardson and C. R. Thorne, "Multiple thread flow and channel bifurcation in a braided river: Brahmaputra-jamuna river, bangladesh," Geomorphology, vol. 38, no. 3-4, pp. 185-196, 2001.

[18] R. V. Santamaria, "Closure of offtakes in Bangladesh: Causes and assessment of remedial measures," 2017.

[19] Z. Wang, M. Vries, R. Fokkink, and A. Langerak, "Stability of river bifurcations in id morphodynamic models," Journal of Hydraulic Research, vol. 33, no. 6, pp. 739-750, 1995

[20] R. Fokkink, Z. Wang, and M. Schropp, "On 1-d morphodynamic network models," in Proc. the Congress-International Association for
Hydraulic Research, vol. 3. Local Organizing Committee of the Xxv Congress, 1995, pp. 104-109.

[21] R. Roosjen and C. Zwanenburg, "Research on bifurcations in rivers," 1995.

[22] G. Akkerman, "Zandverdeling bij splitsingspunten: Literatuurinventarisatie voor inlaten van nevengeulen," Q1573, 1993.

[23] J. Agunwamba and C. Nnaji, "The effects of off take angle on the velocity distribution and rate of siltation of canals," Nigerian Journal of Technology, vol. 28, no. 2, pp. 13-22, 2009.

[24] T. Ahmed, "Experimental study on placement of toe protection elements of river bank protection works under live bed condition," 2014.

[25] L. Malik, "Experimental study of flow and sediment distribution at river offtake," 2018.

[26] H. Bulle, "Investigations "u about the bed load derivation during the splitting of water courses a": model tests from the river engineering laboratory of the Technical University of Karlsruhe," VDI-Verlag, 1926.

[27] P. Ackers and W. R. White, "Sediment transport: New approach and analysis," Journal of the Hydraulics Division, vol. 99, no. hy11, 1973.

[28] F. Engelund and E. Hansen, "A monograph on sediment transport in alluvial streams," Technical University of Denmark 0stervoldgade 10 Copenhagen K., 1967.

[29] L. C. V. Rijn, "Sediment transport, part I: Bed load transport," Journal of Hydraulic Engineering, vol. 110, no. 10, pp. 1431-1456, 1984.

Copyright $\odot 2021$ by the authors. This is an open access article distributed under the Creative Commons Attribution License which permits unrestricted use, distribution, and reproduction in any medium, provided the original work is properly cited (CC BY 4.0).

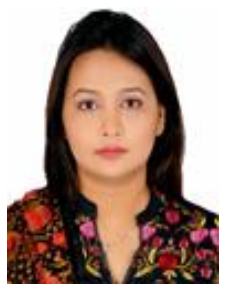

Lamisa Malik was born in January 1990 in Dhaka, Bangladesh. She obtained her B.Sc and M.Sc. degree in Water Resource Engineering from Bangladesh University of Engineer and Technology (BUET) and secured the first position in order of merit. She joined as a Lecturer in the Water Resources Engineering, BUET in 2014 and currently an assistant professor on leave for persuasion of $\mathrm{Ph} . \mathrm{D}$. in the University of Waterloo, Canada. Her research interest is in hydraulics, river engineering, mathematical modelling, hydrology.

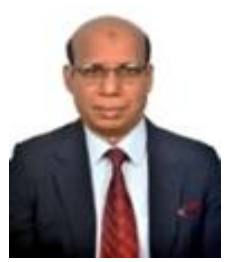

M. Abdul Matin was born in August 1958. M. A. Matin joined BUET in 1981. He is now working as a professor in Water Resources Engineering Department of BUET. He has vast knowledge and experience in the field of water resources engineering. Dr. Matin did his B.Sc. in civil engineering from BUET, the M.Sc.Engg from the same university in water resources engineering. He obtained his Ph.D. in civil engineering (river eng.) degree from the University of Strathclyde, Glasgow, UK. Dr Matin has already supervised significant numbers of PG research-based theses. As a professional, Dr. Matin involved in a number of national-level water-related projects. He has vast research experience in the water-related field and has around 65 publications in national and international journals and proceedings. During his, career, Dr. Matin delivered lectures in waterrelated subjects in many training courses organized by different water sector organizations as a resource person 